\title{
The Effects of Water-Based Exercise on Muscle activity and Gait Ability in Stroke Patients
}

\author{
Seung-Kyu Park', Dae-Jung Yang', Jung-Il Kang', Je-Ho Kim', Sam-Heon Park² \\ 'Department of Physical Therapy, School of Public Health, Sehan University; ${ }^{2}$ Department of Physical Therapy, Graduate School, Sehan University, \\ Yeongam-gun, Jeollanam-do, Korea
}

Purpose: This study attempts to determine the effects of water-based exercise performed on stroke patients in their muscle activity of lower extremity and gait ability tests.

Methods: The subjects were 20 stroke patients, who were randomly divided into a water-based exercise group and a land-based exercise group, each including 10 patients. Both exercises were performed 3 days per week, for 40 minutes a day, for a period of eight weeks.

Results: The water-based exercise group showed a greater increase in muscle activity of lower extremity compared to the land-based exercise group. The water-based exercise group showed a greater increase in gait ability than the land-based group, showing a significant difference and better efficiency of water-based exercise when compared to land-based exercise.

Conclusion: From the result of this study, we found that water-based exercises are more effective in improving muscle activity of lower extremity and gait ability. The patient is considered to be used by itself to involve the treatment and the risk of falling from the lowered state into the treatment method for the intensive treatment of stroke patients to be useful in improving the strength and ability to walk.

Keywords: Water-based exercise, Muscle activity, Gait, Stroke

\section{서 론}

뇌졸중은 출혈 또는 허혈성으로 인한 뇌혈관의 손상으로 인해 대뇌 기능의 국소적인 소실을 나타낸다.' 이로 인해 장애를 유발하는 대표 적인 질병으로 대두 되었으며 생존자에게 지속적인 장애가 되어 삶 의 질을 떨어뜨린다. 대부분의 뇌졸중 환자는 마비측 근육의 변화를 보이며 근육약화, 강직, 구축 등에 밀접한 영향을 미치며 근육의 두께 감소 및 근섬유의 단축 그리고 운동단위(motor unit)의 감소를 나타 낸다. ${ }^{3}$ 이와 같은 근 생리학적 문제는 결국 근력 저하를 나타내고 기 능적 움직임을 위한 협력수축(co-contraction), 등장성 수축(isotonic contraction), 자세 유지능력, 근골격계의 부하 상태 동안 움직임 조절 등 근육의 기본적 능력의 감소를 나타내어 기능적 제한을 보이게 된 다. 또한, 동작 수행 시 운동단위, 골격근 동원의 유지, 분포 및 반복적 인 수행 능력에 문제가 발생하여 정상인보다 근 활동이 부자연스럽 게 커진다. 이러한 비정상적인 근육 동원으로 인해 정적인 자세 유지 시 자세동요가 증가하고 체중지지를 하는 동안 필요한 지구력도 감
소하여 자세를 유지하는 능력의 감소를 보인다고 하였으며, ${ }^{4}$ 이로 인 해 불균형적인 선자세를 하게 되어 비마비측으로 체중지지율의 증가 를 보인다고 하였다. Hornby 등 5 은 뇌졸중 환자의 마비측의 감각저하 와 비대칭적인 수행처리 능력의 저하는 뇌졸중 환자의 자세조절 능 력의 저하는 균형능력의 저하를 야기시켜 보행능력의 감소를 보이게 된다. 이러한 뇌졸중 환자의 균형과 보행능력의 감소는 일상생활활 동에 제한을 주며 개인의 독립성을 저하시키고 결국 사회적 활동의 제약을 초래한다.

보행이란 발뒤굼치와 발바닥이 바닥에 닿는 것으로부터 시작하여 같은 발이 다시 바닥에 닿는 것을 말하고, 한쪽 발이 바닥에 접촉하 여 체중지지가 일어나는 입각기와 발가락 떼기부터 다음 뒤꿈치가 닿기까지의 흔듦기로 나누어진다. 뇌졸중 환자의 보행은 건강한 성인 에 비해 좌우 비대칭적인 모습과 보행 속도, 하지 보장의 차이를 보이 며, ${ }^{6}$ 분속수의 감소, 양발지지기의 증가, 마비측 입각기의 감소와 흔듦 기의 증가를 보인다. 이러한 비대칭적인 자세와 체중이동능력의 저하 로 인해 마비측 사지의 기능을 회복하기 위한 사용의 감소와 비마비 
측만 사용하려는 경향이 높아져 마비측 사지의 기능의 저하를 초래 하게 된다.?

뇌졸중 환자의 급성기 이후 재활을 위한 원동력의 대부분은 정상 적인 보행으로 돌아가기 위함이고, 많은 환자들의 재활의 마지막 목 표를 사회로 복귀와 환자의 독립성을 보장하고 손상 이전의 기능으 로 회복에 있기 때문에 균형과 보행능력은 오랜 세월에 걸쳐 임상적 으로 중요하게 연구되어 왔다. ${ }^{89}$ 현재 반신마비 환자의 기능증진과 보 행능력 증진을 위한 재활프로그램은 과제 지향적 훈련, 과제와 관련 된 순환운동, 청각적 피드백 훈련, 기능적 전기 자극, 승마기구 훈련, 그리고 수중운동 프로그램 등이 있다.

최근 안전하고 효과적인 운동의 필요성이 요구되고 있으며, ${ }^{10}$ 수중 에서 훈련은 낙상 속도를 천천히 할 수 있고, 물의 특성을 이용한 억 제와 촉진을 통해 균형을 유지하거나 자유로운 움직임을 가능하게 한다. 또한, 수중에서 균형훈련 중에는 낙상의 위험성과 이에 따른 두 려움을 감소 시킬 수 있고 유사 낙상에서의 대처 훈련의 하나로 사용 할 수 있다고 하였다." 특히 수중운동 프로그램은 지상에서 체중 부 하를 감당할 수 없는 환자들에게 좀 더 조기에 운동을 시작할 수 있 는 환경을 제공해 주어 아주 가벼운 통증이 있는 상태로도 운동할 수 있으며 관절에 부담을 주지 않으면서 근력 및 활동성, 지구력 등을 향상할 수 있다고 하였으며, ${ }^{12}$ Hauer 등 ${ }^{13}$ 의 연구에 의하면 물의 역학 적 특성들이 신체를 지지하는 작용을 하고 운동 시에 낙상의 두려움 과 급성 손상의 가능성을 줄여 낮은 위험성의 운동 환경을 만들게 되 어 수중환경에서의 운동이 가장 안전하다고 하였다. Masumoto 등 ${ }^{14}$ 은 수중 트레드밀을 적용한 그룹에서 다리 근활성도의 유의한 증가 를 보였으며, Barela와 Duarte ${ }^{15}$ 는 노인을 대상으로 수중에서 보행 훈 련을 실시한 결과 보행능력의 유의한 차이를 보였으며, Kim 등 ${ }^{16}$ 은 뇌 졸중 환자를 대상으로 12 주간 수중재활운동을 실시한 결과 보행능 력의 유의한향상을 보였다

이처럼 수중에서 다양한 훈련을 통해 근력과 균형 및 보행에 대한 연구들은 활발하게 이루어져 왔으나 수중기반 훈련이 뇌졸중 환자 의 보행속도와 지구력이 포함된 보행능력에 대한 연구는 부족한 실 정이다. 따라서 본 연구의 목적은 뇌졸중 환자에게 수중기반 훈련이 다리 근활성도와 보행능력에 미치는 영향에 대해 알아보고자 한다.

\section{연구방법}

\section{1. 연구대상}

본 연구는 2015년 3월 2일부터 4월 25일 까지 8 주간 전남 목포 소재 J 재활병원에서 이루어 졌으며, 발병 6 개월 이상 경과된 뇌졸중 환자 20 명을 대상으로 본 연구의 참여기준에 적합한 자로 본인 또는 보호 자에게 본 연구에 대해 충분히 설명한 후 진행하였고, 각각 실험군 10
Table 1. General characteristics of the subjects

\begin{tabular}{lccc}
\hline Characteristic & $\begin{array}{c}\text { Experimental } \\
\text { group }\end{array}$ & $\begin{array}{c}\text { Control } \\
\text { group }\end{array}$ & $\mathrm{p}^{*}$ \\
\hline Number & 10 & 10 & \\
Age (year) & $56.1 \pm 3.2$ & $51.3 \pm 4.5$ & 0.627 \\
Stroke duration (month) & $15.6 \pm 1.6$ & $16.1 \pm 2.3$ & 0.487 \\
Sex (male/female) & $8 / 1$ & $5 / 4$ & 0.735 \\
Paretic side (right/left) & $8 / 2$ & $7 / 3$ & 0.463 \\
\hline
\end{tabular}

${ }^{*} \mathrm{p}$ : Independent t-test.

명, 대조군 10 명으로 나누어 연구를 진행 하였다. 구체적인 선정조건 은 전문의에게 뇌졸중으로 진단을 받은 자, 한국형 간이정신상태 검 사(Korean Mini Mental State Evaluation, K-MMSE) 결과 24점 이상으 로 인지기능이 정상 범주에 속하는 자, 언어의 사용은 제한적이지만 의사소통이 가능한 자, $10 \mathrm{~m}$ 이상 독립보행이 가능한 자, 수중기반 훈 련 후 빈맥, 불안정 등 심폐기능 이상 소견을 보이는 경우 연구대상에 서 제외하였다(Table 1).

\section{2. 실험방법}

본 연구가 진행되는 풀의 수심은 1.2-1.4 m, 물의 온도는 Cider 등 ${ }^{17}$ 이 사용한 온도로 풀장 내 물의 온도를 일반 수영장의 온도인 $25-28^{\circ} \mathrm{C}$ 보 다 $33-34^{\circ} \mathrm{C}$ 로 높게 유지하여 환자를 체온보다 낮은 온도에서 추위에 떠는 것을 방지함으로써 갑작스런 근 수축을 방지하여 치료의 목적 을 최대로 하였다. ${ }^{18}$ 일반적인 신경계 물리치료를 30 분씩 중재한 후, 8 주간, 3 회/1주, 40 분/1일 동안 시행하였다. 수중기반 훈련을 중재하기 전 충분한 교육을 시행하였으며, 제자리에 서있기, 마비측 다리로 지 지하여 한 발로 서기, 비마비측 다리로 발차기를 포함한 Itshak Melzer 등ㅁㅇㅢ 연구를 기반으로 하여 수중기반 훈련을 시행하였다. 중재는 또 한 수중 훈련 시에 환자가 어지러움, 오심, 가슴에 불편함이 있으면 즉 시 중단하도록 하였다. 지상기반 훈련군은 연구 일반적인 신경계 물 리치료를 30 분씩 중재한 후, 8 주간, 3 회/1주, 40 분/1일 동안 시행하였 다. 지상기반 훈련을 중재하기 전 충분한 교육을 시행하였으며, 평행 봉 사이에서 제자리 서있기, 마비측 다리로 지지하여 한 발로 서기, 비 마비측 다리로 발차기를 포함한 지상기반 훈련을 실시 하였다.18

\section{1) 측정도구}

(1) 표면 근전도 시스템(Surface Electro myography System)

하지의 근활성도를 측정하기 위하여 표면 근전도 시스템(MP100 EMG, Biopac System Inc., USA)을 이용하였고 여기에서 전환된 디지 털 신호는 개인용 컴퓨터에서 Acqknowledge 3.91 소프트웨어를 이용 하여 자료 처리하였다. ${ }^{19}$ 표면 근전도의 신호에 대한 피부 저항을 감 소시키기 위하여 부착부위의 털을 제거한 후, 소독용 알코올로 피부 를 깨끗이 하였다. 근전도 자료는 마비 측의 안쪽 넓은근(Vastus Me- 
dialis), 넙다리 두갈래근(Biceps Femoris), 장딴지근(Gastrocnemius)에 서 수집하였고 표본추출률(Sampling rate)은 $1,024 \mathrm{~Hz}$ 로 설정하였고, 잡음을 최소화하기 위하여 대역 여과 필터(notch filter) $60 \mathrm{~Hz}$, 대역통 과필터(band pass filter) 30-500 Hz를 사용하였고, 수집된 신호는 실효 치(RMS)로 변환하였다. 근전도 신호를 정량화하기 위해 특정 동작의 근수축을 기준 수축(Reference Voluntary Contraction, RVC)으로 하여 이를 표준화 하는 백분위 기준 수축(\%RVC) 방법을 이용하였다. 기준 수축은 반웅크리기(semi-squat) 자세를 유지하는 동안 마비 측 다리 의 근활성도를 측정한 뒤 처음과 마지막 1 초씩을 제외한 3 초의 신호 를 이용하여 기준수축 값을 산출하고, 체중지지기를 하는 동안 마비 측 다리의 근활성도 값과 비교하여 \%RVC값을 산출하였다. 본 연구 에서는 마비 측의 측정값만 사용하였다. ${ }^{20,21}$

(2) 일어나 걸어가기 검사(Timed Up and Go test, TUG)

TUG 검사는 환자의 기능적인 운동성과 이동능력, 균형을 빠르게 측 정할 수 있는 검사방법으로, 팔걸이가 있는 의자에 앉아 실험자의 출 발 신호와 함께 의자에서 일어나 $3 \mathrm{~m}$ 거리를 걸어서 다시 돌아와 의 자에 앉는 시간을 측정하는 방법으로 측정자내 신뢰도는 $r=0.99$ 이 고, 측정자 간 신뢰도는 $r=0.98$ 이다. 일반적으로 20 초 이상이면 기능 적인 운동손상이 있음을 의미하고, 이 검사는 일반노인의 균형능력 과 기능적인 운동을 평가하여 넘어짐 예측에 사용되어 왔고, 최근에 는 일반노인, 뇌졸중, 파킨슨질환, 관절염 환자의 기능적 운동성과 이 동능력의 평가에 적용되고 있다.22

(3) $10 \mathrm{~m}$ 보행 속도 검사(10 m walk test, $10 \mathrm{mWT}$ )

$10 \mathrm{mWT}$ 검사는 보행 수행능력을 평가하기 위한 도구이며 여러 연구 에서 신뢰도와 타당도가 검증된 검사방법으로, $14 \mathrm{~m}$ 의 직선거리에서 시작과 끝의 $2 \mathrm{~m}$ 를 감속과 가속을 위한 거리로 설정하고 $10 \mathrm{~m}$ 의 거리 에 대한 보행 시간을 측정하여 기능적 보행을 위한 측정 변수로 사용 하였으며 높은 신뢰도를 나타내는 평가 도구이다. ${ }^{23}$

(4) 6 분 보행 검사(6 minute walk test, $6 \mathrm{MWT})$

$6 \mathrm{MWT}$ 는 신체적 능력을 측정하기 위한 검사이며, 일상적인 신체 활
동과 유사한 최대하 수준의 기능적 평가도구로, 지구력과 장거리를 걸을 수 있는 능력을 평가한다. ${ }^{24}$ 검사의 시작은 정해진 트랙을 따라 6 분 동안 걷는 방법이다. 검사 전 준비운동은 시행하지 않았고, 시작 전 의자에 앉은 상태에서 검사방법에 대한 교육을 하였다. 대상자에 게 6 분간 최대한 많은 거리를 걷도록 하였으며, 걷는 속도는 개인 스 스로 조절하도록 하였다. 대상자가 검사를 시작한 후에는 남은 시간 과 지침에서 허용된 문구 “잘하고 있어요" "계속 하세요”만을 사용하 였다. 검사가 종료된 다음에는 의자에 앉아 휴식을 취하게 하였다.

\section{2) 분석방법}

결과분석은 WINDOW SPSS 20.0 프로그램을 이용하여 처리하였다. 연구대상자의 동질성 검증을 위해 독립표본 t-검정(independent t-test) 을 실시하였고, 운동방법에 따른 그룹 간 근활성도와 보행능력을 비 교하기 위해 공분산분석(analysis of covariance, ANCOVA)을 실시하 였다. 통계학적 유의수준은 0.05 로 하였다.

\section{결 과}

\section{1. 그룹 간 근활성도 비교}

그룹 간 중재 전후 안쪽 넓은근의 근활성도 비교에서 실험군은 21.99 $\pm 1.26 \%$ 에서 $46.22 \pm 1.63 \%$ 로, 대조군은 $21.61 \pm 1.01 \%$ 에서 $38.12 \pm 1.42 \%$ 로 대조군과 비교하여 통계학적으로 유의한 차이가 있었다 $(\mathrm{p}<0.05)$. 넙다리 두갈래근의 근활성도는 실험군은 $18.01 \pm 3.34 \%$ 에서 $28.67 \pm$ $1.25 \%$ 로, 대조군은 $18.09 \pm 1.38 \%$ 에서 $22.24 \pm 2.91 \%$ 로 대조군과 비교하 여 통계학적으로 유의한 차이가 있었다 $(\mathrm{p}<0.05)$. 장딴지근의 근활성 도는 실험군은 $11.47 \pm 2.53 \%$ 에서 $17.78 \pm 3.66 \%$ 로, 대조군은 $10.33 \pm$ $3.8 \%$ 에서 $14.16 \pm 1.49 \%$ 로 대조군과 비교하여 통계학적으로 유의한차 이가 있었다 $(\mathrm{p}<0.05)$ (Table 2).

\section{2. 그룹 간 보행능력 비교}

일어나 걸어가기 검사는 중재 전후 실험군에서 $22.08 \pm 2.65 \mathrm{sec}$ 에서 $16.65 \pm 1.98 \mathrm{sec}$ 로, 대조군은 $21.37 \pm 1.56 \mathrm{sec}$ 에서 $18.49 \pm 2.09 \mathrm{sec}$ 로 통계 학적으로 유의한 차이가 있었다 $(\mathrm{p}<0.05) .10 \mathrm{~m}$ 보행 속도 검사 $(10$

Table 2. Comparison of muscle activity between groups

(Unit: \%)

\begin{tabular}{|c|c|c|c|c|c|c|}
\hline \multirow{3}{*}{ Test } & \multicolumn{2}{|c|}{ Pre-test } & \multicolumn{2}{|c|}{ Post-test } & \multirow{3}{*}{$\mathrm{F}$} & \multirow{3}{*}{$\mathrm{p}^{+}$} \\
\hline & Experiment & Control & Experiment & Control & & \\
\hline & \multicolumn{2}{|c|}{ Mean \pm SD } & \multicolumn{2}{|c|}{ Mean $\pm S D$} & & \\
\hline VM & $21.99 \pm 1.26$ & $21.61 \pm 1.01$ & $46.22 \pm 1.63$ & $38.12 \pm 1.42$ & 5.097 & $0.006^{*}$ \\
\hline $\mathrm{BF}$ & $18.01 \pm 3.34$ & $18.09 \pm 1.38$ & $28.67 \pm 1.25$ & $22.24 \pm 2.91$ & 6.209 & $0.001 * *$ \\
\hline GC & $11.47 \pm 2.53$ & $10.33 \pm 3.85$ & $17.78 \pm 3.66$ & $14.16 \pm 1.49$ & 3.714 & $0.035^{*}$ \\
\hline
\end{tabular}

VM: Vastus medialis, BF: Biceps femoris, GC: Gastrocnemius.

${ }^{+} p=$ ANCOVA, ${ }^{*} p<0.05,{ }^{* *} p<0.005$. 
Table 3. Comparison of gait ability between groups

\begin{tabular}{|c|c|c|c|c|c|c|}
\hline \multirow{3}{*}{ Test } & \multicolumn{2}{|c|}{ Pre-test } & \multicolumn{2}{|c|}{ Post-test } & \multirow{3}{*}{$\mathrm{F}$} & \multirow{3}{*}{$\mathrm{p}^{+}$} \\
\hline & Experiment & Control & Experiment & Control & & \\
\hline & \multicolumn{2}{|c|}{ Mean $\pm S D$} & \multicolumn{2}{|c|}{ Mean $\pm S D$} & & \\
\hline TUG (second) & $22.08 \pm 2.65$ & $21.37 \pm 1.56$ & $16.65 \pm 1.98$ & $18.49 \pm 2.09$ & 1.655 & $0.021^{*}$ \\
\hline $10 \mathrm{mWT}$ (second) & $27.25 \pm 1.90$ & $26.37 \pm 2.76$ & $22.02 \pm 1.88$ & $23.89 \pm 2.39$ & 8.625 & $0.026^{*}$ \\
\hline $6 \mathrm{MWT}(\mathrm{m})$ & $101.76 \pm 3.63$ & $100.85 \pm 2.87$ & $122.96 \pm 2.88$ & $115.72 \pm 3.92$ & 7.878 & $0.004^{* *}$ \\
\hline
\end{tabular}

TUG: Timed Up and Go Test, $10 \mathrm{mWT:} 10 \mathrm{~m}$ Walk Test, 6 MWT: 6 Minute Walk Test.

${ }^{+} p=$ ANCOVA, ${ }^{*} p<0.05,{ }^{* *} p<0.005$.

$\mathrm{mWT}$ )는 중재 전후 실험군에서 $27.25 \pm 1.90 \mathrm{sec}$ 에서 $22.02 \pm 1.88 \mathrm{sec}$ 로, 대조군은 $26.37 \pm 2.76 \mathrm{sec}$ 에서 $23.89 \pm 2.39 \mathrm{sec}$ 로 통계학적으로 유의한 차이가 있었다 $(\mathrm{p}<0.05)$. 6 분 보행 검사 $(6 \mathrm{MWT})$ 는 중재 전후 실험군 에서 $101.76 \pm 3.63 \mathrm{~m}$ 에서 $122.96 \pm 2.88 \mathrm{~m}$ 로, 대조군은 $100.85 \pm 2.87 \mathrm{~m}$ 에서 $115.72 \pm 3.92 \mathrm{~m}$ 로 통계학적으로 유의한 차이가 있었다 $(\mathrm{p}<0.05)$ (Table 3).

\section{고 찰}

뇌졸중은 혈액 공급 제한 혹은 뇌 조직 내의 출혈에 의한 세포 손상 과 신경학적 기능 결손의 결과이다. ${ }^{2}$ 이와 함께 뇌졸중 환자는 마비 측 근육약화, 강직, 구축 등과 같은 근육의 변화를 동반하여, 근육의 두께 감소 및 근섬유의 단축 그리고 운동단위 수의 감소를 나타낸다. 특히 다리의 약한 근력과 운동조절의 저하, 경직 혹은 대항근의 공동 수축 및 체중지지 시 불안정성으로 인하여 대부분의 뇌졸중 환자는 같은 나이의 정상인에 비해 선 자세에서의 자세동요(postural sway)가 커지며, 안정성 한계도 감소한다. 이러한 요인으로 인하여 움직임을 할 때 1.5-2배의 에너지 소비를 한다.

많은 재활 프로그램들은 뇌졸중 환자의 기능과 보행능력의 회복 을 위한 프로그램들이 많은데, 최근 수중물리치료가 뇌졸중 환자뿐 만 아니라 다양한 분야에 걸쳐 사용되어진다.12 수중운동은 중력을 감소시켜 지상에서보다 움직임이 좀 더 쉬워지고 오락적 요소로 환 자의 참여를 유도할 수 있다. 또한, 부력의 영향으로 신체에 가해지는 중력이 관절에 가해지는 부담이 감소하게 된다. 이러한 효과로 인해 다양한 과제들을 수행하고, 수중에서 훈련을 통해 안전하고 넓은 가 동범위에서 운동이 가능하게 하여, ${ }^{13}$ 사용이 제한되었던 근육과 관절 에 부담을 감소시켜 아주 작은 힘으로도 움직임을 가능할 수 있도록 한다. 이와 더불어 물리적 안정감을 제공받아 지상에서보다 도전적 인 과제들을 수행할 수 있게 되므로 산소섭취량 및 심박수가 증가되 고, ${ }^{25}$ 낙상에 대해 두려움을 줄인 상태에서 신체적 능력을 향상시킬 수 있다.26,27 넓은 범위와 도전적인 과제들을 통해 움직임들이 제한된 근육들을 자극하여 보행에서 사용되는 근육들을 지상에서보다 활
성화시켜 보행능력과 근력에 유의한 향상을 가져 온다고 하였다.

Kaneda 등 ${ }^{28}$ 의 연구에서 건강한 성인 남성에서 수중 훈련을 적용 하였을 때 다리 근활성도에 유의한 차이가 있었으며, Masumoto 등'14 의 노인과 성인들을 대상으로 수중훈련을 실시한 결과 노인 그룹에 서 다리 근활성도의 유의한 차이를 보였다. 또한 $\mathrm{Kim}^{29}$ 은 뇌졸중 환 자 들을 대상으로 12 주간 수중 훈련을 실시한 결과 하지 근력 및 보행 속도와 다리 근활성도의 증가를 보였다. 본 연구에서도 다리 근활성 도에서 향상되는 동일 한 결과를 얻었지만 Kotani 등 ${ }^{30}$ 은 유속의 변 화를 통한 수중훈련을 실시한 결과 다리 근활성도에 유의한 차이가 없다고 하였다. 이는 유속의 변화를 통해 대상자에서 외력이 작용하 게 되어 넘어지는 것에 대한 저항을 이겨내기 위한 것으로 사료되며, 본 연구에서는 환자가 동작을 수행하는데 수중이라는 환경의 특성 이 주는 안정감과 대상자 스스로 치료에 참여하고 강도와 동작의 범 위를 지상에서보다 더 넓은 범위에서 신체 조절능력의 증가로 인해 다리 근활성도에 유의한 차이를 나타낸 것으로 생각되어진다.

Barela 드이의 연구에서 수중에서 훈련 시 보행속도의 증가를 보였 다. Chu 등 ${ }^{22}$ 의 연구에서도 뇌졸중 환자를 대상으로 수중훈련을 실시 한 결과 보행 속도의 유의한 차이를 나타내었으며, Lee 33 은 뇌졸중 환 자를 대상으로 수중훈련을 실시한 결과 일어나 걸어가기 검사에서 유의한 차이를 보였다. Volaklis 등 34 은 수중 운동을 통해서 보행에 필 요한 근육들의 활성도가 높아져 보행속도의 향상을 가져 온다고 하 였다. 또한 Barela 드이은 수중훈련을 통해 엉덩관절 굴곡근 활동의 증 가가 보행속도의 증가를 가져온다고 하였다. 본 연구 결과에서도 수 중기반 훈련을 실시한 실험군이 지상기반 훈련을 실시 대조군에 비 해 보행능력의 유의하게 증가함을 보였는데, 이는 단순히 보행 속도 뿐만 아니라 보행 지구력에서도 유의한 향상을 보여 선행연구와 일 치하였다.

본 연구의 결과를 살펴보면 종아리근, 안쪽 넓은근, 넙다리 두갈래 근의 근활성도와 일어나 걷어가기 검사, $10 \mathrm{~m}$ 보행 속도 검사, 6 분 보 행 검사에서 수중기반 훈련을 실시한 실험군이 지상기반 훈련을 실 시한 대조군에서 보다 통계학적으로 유의한 결과를 확인할 수 있었 다. 지상기반 훈련을 실시한 대조군에서도 하지 주요 근육의 근활성 
도와 일어나 걷어가기 검사, $10 \mathrm{~m}$ 보행 속도 검사, 6 분 보행 검사에서 통계학적인 유의한 결과가 나타났으나, 수중기반 훈련에 비교했을 때 수중기반 훈련이 지상기반 훈련보다 효과적인 중재방법임을 알 수 있 었고, 수중기반 훈련을 통해 하지 기능의 향상과 함께 주요근육의 근 활성도가 증가하고, 이에 따라 일상생활 동작에서의 긍정적인 효과 도 입증할 수 있었다. 중재 적용 시 대상자가 낙상에 대한 두려움 없이 보다 넓은 범위에서 스스로 훈련에 참여하려는 의지도 높았으며, 안 정적이고 다양한 범위의 훈련을 수행하여 뇌졸중 환자의 보행능력 의 증진을 위해 적극적으로 고려되어야 할 중재방법이 될 수 있을 것 이라 생각되어진다.

본 연구의 제한점은 연구 대상자의 손상 부위와 발병 후 유병기간 등의 관련인자가 연구에 미치는 영향을 완전히 배제하기 어려웠고, 대상자의 수가 적기 때문에 일반화하기 어려움이 있었으며, 연구 대 상자의 일상생활 통제에 어려움이 있었다. 향후 본 연구를 바탕으로 뇌졸중 환자에게 수중기반 훈련을 통한 근력강화가 심호흡계통의 기 능과 삶의 질에 미치는 영향에 대한 추가적인 임상적인 연구가 필요 할 것으로 사료된다.

\section{ACKNOWLEDGEMENTS}

The Research has been conducted by the Research Grant of Sehan University in 2015 .

\section{REFERENCES}

1. Peurala SH, Kononen P, Pitkanen K et al. Postural instability in patients with chronic stroke. Restorative neurology and neuroscience. 2007; 25(2):101-8.

2. Lamb SE, Ferrucci L, Volapto S et al. Risk Factors for Falling in HomeDwelling Older Women With Stroke The Women's Health and Aging Study. Stroke. 2003;34(2):494-501.

3. Leroux A, Pinet H, Nadeau S. Task-oriented intervention in chronic stroke: changes in clinical and laboratory measures of balance and mobility. Am J Phys Med Rehabil. 2006;85(10):820-30.

4. Hausdorff JM, Ring H. Effects of a new radio frequency-controlled neuroprosthesis on gait symmetry and rhythmicity in patients with chronic hemiparesis. Am J Phys Med Rehabil. 2008;87(1):4-13.

5. Hornby TG, Campbell DD, Kahn JH et al. Enhanced gait-related improvements after therapist-versus robotic-assisted locomotor training in subjects with chronic stroke a randomized controlled study. Stroke. 2008;39(6):1786-92.

6. Hsu AL, Tang PF, Jan MH. Analysis of impairments influencing gait velocity and asymmetry of hemiplegic patients after mild to moderate stroke. Arch Phys Med Rehabil. 2003;84(8):1185-93.

7. Campbell FM, Ashburn AM, Pickering RM et al. Head and pelvic movements during a dynamic reaching task in sitting: Implications for physical therapists. Arch Phys Med Rehabil. 2001;82(12):1655-60.

8. Maeshima S, Osawa A, Miyazaki Y et al. Functional outcome in patients with pontine infarction after acute rehabilitation. Neurological Sciences. 2012;33(4):759-64.

9. Dickstein R, Abulaffin N. Postural sway of the affected and nonaffected pelvis and leg in stance of hemiparesis patients. Arch Phys Med Rehabil. 2000;81(3):364-7.

10. Cho YM. The effect of hydrotherapy on the balance in stroke patient. Chonnam National University. Dissertation of Master's Degree. 2009.

11. Melzer I, Elbar O, Tsedek I et al. A water-based training program that include perturbation exercises to improve stepping responses in older adults: study protocol for a randomized controlled cross-over trial. BMC geriatrics. 2008;8(1):19.

12. Park J, Lee D, Lee S et al. Comparison of the effects of exercise by chronic stroke patients in aquatic and land environments. J Kor Phys Ther. 2011;23(5):821-4.

13. Hauer K, Specht N, Schuler M et al. Intensive physical training in geriatric patients after severe falls and hip surgery. Age and ageing. 2002;31(1): 49-57.

14. Masumoto K, Shono T, Takasugi SI et al. Age-related differences in muscle activity, stride frequency and heart rate response during walking in water. J Electromyogr and Kinesiol. 2007;17(5):596-604.

15. Barela AM, Duarte M. Biomechanical characteristics of elderly individuals walking on land and in water. J Electromyogr and Kinesiol. 2008; 18(3):446-54.

16. Kim HM, Woo SY, Kim KU. Gait Comparison of the Stroke Patients' Ground \& Aqua-rehabilitation Program for One Year after 12 Weeks Aqua-rehabilitation Program. J Adapted Phys Activity \& Exercise. 2007; 15(4):245-59.

17. Cider A, Sunnerhagen KS, Schaufelberger M et al. Cardiorespiratory effects of warm water immersion in elderly patients with chronic heart failure. Clinical physiology and functional imaging. 2005;25(6):313-7.

18. Park SK. Park SH. The Effects of Water-Based Exercise on Physiological Cost Index and Balance in Stroke Patients. J Kor Phys Ther. 2014;26(6): 411-7.

19. Park SK, Yang DJ, Kang JI et al. Biomechanical Analysis of Sitting Up from a Lying Posture in Stroke Patients. J Kor Phys Ther. 2013:25(2):1039 .

20. Kim JH. The effects of whole body vibration exercise on jump performance and quadriceps muscle activation in soccer player. J Kor Phys Ther. 2015;27(3):129-34.

21. Park SK. Kim JH. Effects of EMG-biofeedback Training on Total Knee Replacement Patients' Lower Extremity Muscle Activity and Balance. J Kor Phys Ther. 2013;25(2):81-7.

22. Morris S, Morris ME, Iansek R. Reliability of measurements obtained with the Timed "Up \& Go" test in people with Parkinson disease. Physical therapy. 2001;81(2):810-8.

23. Dobkin BH. Short-distance walking speed and timed walking distance: redundant measures for clinical trials?. Neurology. 2006;66(4):584-6.

24. Bennell K, Dobson F, Hinman R. Measures of physical performance assessments: Self-Paced Walk Test (SPWT), Stair Climb Test (SCT), Six Minute Walk Test (6MWT), Chair Stand Test (CST), Timed Up \& Go (TUG), Sock Test, Lift and Carry Test (LCT), and Car Task. Arthritis care \& research. 2011;63(S11):S350-70. 
25. Ryan AS, Dobrovolny CL, Silver KH et al. Cardiovascular fitness after stroke: role of muscle mass and gait deficit severity. J Stroke and Cerebrovascular Diseases. 2000;9(4):185-91.

26. Lee JR. Difference of Physical Fitness and Blood Lipid by types of the Aquatic Exercise Programs in the Elderly Women. Korea National Sport University. Dissertation of Master's Degree. 2007.

27. Masumoto K, Shono T, Hotta N et al. Muscle activation, cardiorespiratory response, and rating of perceived exertion in older subjects while walking in water and on dry land. J Electromyogr \& Kinesiol. 2008; 18(4):581-90.

28. Kaneda K. Wakabayashi H. Sato D et al. Lower extremity muscle activity during deep-water running on self-determined pace. J Electromyogr \& Kinesiol. 2008;18:965-72.

29. Kim KE. The Effect of the Aqua-Rehabilitation Program on the Stroke Patient's Biomechanical Variables Factors and ADL Performance. SeJong University. Dissertation of Doctorate Degree. 2005.
30. Kotani K. Hirato Y. Ishigaki T et al. Biomechanical analysis of walking through a hallway under flooded conditions. J Physiol \& Anthropol. 2008;28(1):23-8.

31. Barela AMF, Stolf SF, Duarte M. Biomechanical characteristics of adults walking in shallow water and on land. J Electoromyogr \& Kinesiol. 2006; 16:250-6.

32. Chu KS, Eng JJ, Dawson AS et al. Water-based exercise for cardiovascular fitness in people with chronic stroke: A randomized controlled trial. Arch Phys Med Rehabil. 2004;85(6):870-4.

33. Lee DJ. A study on effect of task-related training in water and on land for chronic stroke patient for a balance, functional performance and the quality of the life. Sahm Yook University. Dissertation of Doctorate Degree. 2005.

34. Volaklis KA, Spassis AT, Tokmakidis SP. Land versus water exercise in patients with coronary artery disease: effects on body composition, blood lipids, and physical fitness. Am heart J. 2007;154(3):560-e1. 